\title{
Spinal disorders mimicking infection
}

\author{
Sana Boudabbous ${ }^{1,2^{*}}$ (D) Emilie Nicodème Paulin ${ }^{3}$, Bénédicte Marie Anne Delattre ${ }^{1,2}$, Marion Hamard ${ }^{1}$ and \\ Maria Isabel Vargas ${ }^{2,4}$
}

\begin{abstract}
Spinal infections are very commonly encountered by radiologists in their routine clinical practice. In case of typical MRI features, the diagnosis is relatively easy to interpret, all the more so if the clinical and laboratory findings are in agreement with the radiological findings. In many cases, the radiologist is able to make the right diagnosis, thereby avoiding a disco-vertebral biopsy, which is technically challenging and associated with a risk of negative results. However, several diseases mimic similar patterns, such as degenerative changes (Modic) and crystal-induced discopathy. Differentiation between these diagnoses relies on imaging changes in endplate contours as well as in disc signal. This review sought to illustrate the imaging pattern of spinal diseases mimicking an infection and to define characteristic $\mathrm{MRI}$ and $\mathrm{CT}$ patterns allowing to distinguish between these different disco-vertebral disorders. The contribution of advanced techniques, such as DWI and dual-energy CT (DECT) is also discussed.
\end{abstract}

Keywords: Spondylodiscitis, Magnetic resonance imaging, Inflammation, Degenerative

\section{Key points}

- Spondylodiscitis in elderly patients is challenging in presence of inflammatory Modic changes.

- Features of Anteroposterior inflammatory spine is suggestive of metabolic disease.

- Approach of destructive spondylodiscitis should be integrated in clinical context.

- CT is complementary to MRI to assess osseous changes and detect calcifications.

- 5-Disco-vertebral biopsy could be avoided by systematic analysis of vertebral endplates signal.

\section{Introduction}

Spondylodiscitis represents $2-7 \%$ of all osteomyelitis cases, with an annual incidence of $1 / 100,000$ to $1 / 250,000$ [1-3]. Disco-vertebral biopsy is usually not mandatory if

\footnotetext{
*Correspondence: sana.boudabbous@hcuge.ch

1 Division of Radiology, Department of Diagnosis, Geneva University Hospitals, Rue Gabrielle-Perret-Gentil 4, 1211 Geneva 14, Switzerland ${ }^{2}$ Faculty of Medicine of the Geneva University, Geneva, Switzerland

Full list of author information is available at the end of the article
}

a pathogenic agent is detected by blood culture, yet the detection rate is low (24\%) [4]. Symptoms are initially non-specific and the diagnosis is frequently delayed for 2 to 6 weeks [5]. Neurological symptoms, such as leg weakness, sensory deficit, or radiculopathy, are present in one-third of cases [6]. CT guided biopsy for identifying the pathogenic agent is mainly indicated in atypical and mycobacterial infections in order to choose the appropriate treatment. However, this technique is invasive and at times challenging, notably in kyphotic patients. In addition, it may be associated with complications, particularly in case of difficult access, high risk of bleeding, or high risk of injuries to not-targeted organs R1 Point 1 even if recent studies report high accuracy and safety in expert hands [7-9]. Not to mention that the success rate is lowto-moderate, ranging from 28.1 to $57.1 \%$ [10, 11]. Moreover, pathogenic agent detection is lower in sclerotic areas [1]. C-reactive protein (CRP) levels higher than $50 \mathrm{mg} / \mathrm{L}$ as well as the presence of a paravertebral phlegmon, soft tissue abscess, or epidural abscess are correlated with a higher rate of positive biopsy results [1]. In this review, the most common and reliable MRI and CT features of metabolic and degenerative disorders mimicking spondylodiscitis will be described and illustrated. The 
imaging pattern of these differential diagnoses will also be discussed.

\section{Technical imaging}

MRI is the technique of choice in the acute phase of spondylodiscitis, with a sensitivity of up to $92 \%$ (increased to $95 \%$ when using a contrast agent) and a specificity of up to $96 \%$ [12]. No difference has been reported according to the MRI field strength (1.5 or $3 \mathrm{~T}(\mathrm{~T})$ ) based on morphological T1 and T2WI. STIR is usually used to better detect edema. Sagittal planes are preferred and have to be completed by axial planes for better visualization and delineation of phlegmon or abscesses. Fat-saturation T1WI following contrast agent administration are additionally used to highlight the inflammatory process and detect abscesses. DWI has been used more recently mainly to distinguish between spondylodiscitis and degenerative disorders as well as spinal tumor involvement, with ADC values of inflammatory endplates determined at 1.5 and $3 \mathrm{~T}$ [13]. R2 Point 1 Hence, ADC values for spinal infection oscillated between 1.27 and $1.52 \times 10^{-3} \mathrm{~mm}^{2} / \mathrm{s}$ depending on b-value $[12,14,15]$.

However, the choice of b-value is an important point to consider when analyzing these results. Several authors [14-17] concluded that correct choice of b-value is mandatory for interpreting this sequence (sensitive to both perfusion and cellular density when low and only to cellular density when high), the solution being to use a relatively high b-value without compromising the signal-to-noise ratio. An example of protocol with detailed parameters as performed in our institution at 1.5 and $3 \mathrm{~T}$ is provided in Table 1 .

CT is used to guide percutaneous biopsy, permitting to identify the causative microbiological agent and to exclude malignancy and mimicking diagnoses [1].
In addition, 3D reconstructions are useful for surgeons when spinal fixation is planned [18].

Dual-energy CT (DECT) is a technique enabling tissue quantification based on energy dependence at different $\mathrm{X}$-ray spectra [19]. It is used to assess bone infiltration, such as in multiple myeloma, degenerative diseases like disc herniation [20], and gout. DECT-evidence of urate deposition is considered as a criterion for gout, with this imaging modality having a high sensitivity and specificity ( $87 \%$ and $84 \%$, respectively) [21], but strong data are lacking for the spine. Radionuclide imaging is a useful alternative to MRI when the latter is contraindicated, 18F-fluorodeoxyglucose $\left({ }^{18} \mathrm{~F}\right.$-FDG) being the radiotracer of choice [22, 23]. R1 Point $3{ }^{18} \mathrm{~F}-\mathrm{FDG}$ is a reliable technique to monitor response to treatment with high sensitivity and specificity $[24,25]$. X-ray is no longer used in the diagnostic setting due the delay ( 2 to 8 weeks) in the appearance of radiographic features [26] and the risk of missing the diagnosis in the degenerative spine [27]. Nowadays, this modality, performed in loading position, is reserved to preoperative assessment of spinal deformation.

\section{Imaging pattern of infectious spondylodiscitis}

The typical MRI pattern in the acute stage consists of inflammatory endplates that appear hyperintense on $\mathrm{T} 2$ and STIR and hypointense on T1, along with disc hypersignal (in mirror) [22]. Hyperintensity on T2 and STIR sequences typically involves the entire disc, with enhancement after contrast agent administration and loss of intranuclear cleft. This feature is also known as the "hot disc sign" [28]. Although regarded as controversial in some studies [29], it is highly suggestive of spondylodiscitis (more than $90 \%$ of infection cases). Paraspinal or epidural abscesses are complications of spondylodiscitis

Table 1 Technical MRI protocol of spondylodiscitis at 3 Tesla

\begin{tabular}{|c|c|c|c|c|c|c|c|c|}
\hline Sequence & Acquisition time & TE/TR (ms) & $\mathrm{TI}$ (ms) & $\mathrm{FOV}(\mathrm{mm})$ & Matrix & $\begin{array}{l}\text { Slice } \\
\text { thickness } \\
(\mathrm{mm}) / \mathrm{gap}\end{array}$ & Voxel size & $\begin{array}{l}\text { Parallel imaging } \\
\text { acceleration factor } \\
\text { (GRAPPA) }\end{array}$ \\
\hline t2 tse sag (3 stacks) & $3 \min 39 \times 3$ & $102 / 3500$ & & 270 & 384 & $4 / 10 \%$ & $0.4 \times 0.4$ & 2 \\
\hline t1 tse sag (3 stacks) & $1 \min 59 \times 3$ & $9 / 450$ & & 270 & 320 & $4 / 10 \%$ & $0.8 \times 0.8$ & 2 \\
\hline t2 tirm sag (3 stacks) & $3 \min 51 \times 3$ & $36 / 3700$ & 220 & 270 & 320 & $4 / 10 \%$ & $0.8 \times 0.8$ & 2 \\
\hline t2 tirm cor (psoas) & $4 \min 35$ & $36 / 3700$ & 220 & 340 & 84 & $4 / 10 \%$ & $0.9 \times 0.9$ & 2 \\
\hline Diffusion resolve $e^{* *}$ & $5 \min 09$ & $60 / 95 / 2630^{*}$ & & 220 & 128 & $4 / 10 \%$ & $1.7 \times 1.7$ & 2 \\
\hline $\begin{array}{l}\text { t1 tse dixon sag with Gd (3 } \\
\text { stacks) }\end{array}$ & $3 \min 03 \times 3$ & $11 / 500$ & & 270 & 320 & $4 / 10 \%$ & $0.8 \times 0.8$ & 2 \\
\hline t1 tse fatsat tra with Gd & $2 \min 41$ & $11 / 717$ & & 190 & 256 & $4 / 10 \%$ & $0.7 \times 0.7$ & 2 \\
\hline
\end{tabular}

TSE, TurboSpinEcho; Sag, sagittal; Cor, coronal; Fatsat, fat saturation; Tra, transverse; Gd, gadolinium; min, minute; mm, millimetre; ms, millisecond; TE, echo time; TR, repetition time; TI, inversion time

*Resolve sequence has $2 \mathrm{TE}$

**Sag $4 \mathrm{~b}$ values (b0, 300, 600, 800) 
and they appear in high signal intensity on T2WI and STIR sequences, and in low signal intensity with annular or heterogeneous enhancement on T1WI. Erosions are a late feature and indicate a subacute progress. On DWI, the mean ADC of infectious spondylodiscitis was lower $\left(1.27 \pm 0.38 \times 10^{-3} \mathrm{~mm}^{2} / \mathrm{s}\right)$ than for the control group, but higher than in patients with degenerative discitis [9]. For other authors, the ADC cut-off value for spinal infection was $1.52 \times 10^{-3} \mathrm{~mm}^{2} / \mathrm{s}$ when using a b-value of $800 \mathrm{~s} / \mathrm{mm}^{2}$ [14-17]. Patel et al. demonstrated that R2 point 2 the preservation of linear regions of high signal situated within the adjacent vertebral bodies, described as the "claw sign", can be used to distinguish between degenerative changes in the spine (Modic 1), in which case the claw sign is present, and spondylodiscitis, in which case MRI shows heterogeneous amorphous hyperintensity or absent crab's claw sign [30]. Sequences allowing generating several contrasts as well as quantifying T1 and $\mathrm{T} 2$ relaxation times, such as synthetic imaging or fingerprinting, are promising to differentiate between spondylodiscitis and metabolic or degenerative diseases using quantitative imaging [31]. Spondylodiscitis CT features depend on the osteitis stage. Lytic defects (erosions) of the endplates without sclerotic margins indicate an earlier stage [32]. Besides, a sclerotic pattern of endplates is correlated with a higher risk of negative biopsy [32]. CT remains the technique of choice to assess spinal calcifications [20].

R1 Point 2 On the other hand, differentiation between pyogenic and tuberculosis spondylodiscitis based only on imaging remains challenging. The presence of an intact meningo-vertebral ligament (posterior midvertebral septum) [33], thoracic involvement, subligamentous extension, skip lesions, importance of abscesses and kyphotic deformity [34] as well as disc space sparing and vertebral body collapse [35] are suggestive of tuberculosis.

Finally, imaging criteria could be integrated in a scoring system for the diagnosis and to monitor progression following treatment [36].

\section{Imaging findings of diseases mimicking spinal infection on MRI}

The typical MRI characteristics are summarized in Table 2, which is provided as a guide to differentiate diseases mimicking infectious spondylodiscitis according to signal intensity changes and additional X-ray and CT characteristic features.

\section{Modic 1 degenerative changes of the endplate}

Degenerative spinal disorders in the inflammatory stage (Modic 1) can mimic infection particularly due to an overlapping clinical presentation (acute spinal pain and inflammatory laboratory findings). The vertebral endplate changes are related to inflammation-mediated active disc degeneration [37, 38]. On the other hand, the increased vascularity seen in Modic 1 predisposes to non-specific, low-grade bacterial infections. For vascular and biomechanical reasons, Modic lesions and spondylodiscitis have a similar location, R2 point 3 predominantly affect the lumbar levels [39]. Conventional $\mathrm{CT}$ is sensitive to endplate destruction, with a very good specificity. It appears irregular and can be associated with subchondral cysts, but edema cannot be visualized in early stages [40]. There are no available data in the literature regarding assessment of Modic lesions by DECT. On MRI, bone marrow edema appears hypointense on T1WI and hyperintense on T2WI and STIR, with a pattern of claw sign on DWI. Abnormal disc signal intensity and contrast enhancement are non-specific patterns (Fig. 1). Moreover, endplate erosions are seen in infections and in degenerative processes due to osteochondrosis. Thus, morphological differentiation is important and can be assessed using several features. Schwartz-Nemec et al. [41] showed that endplate contours, irregular but intact in Modic 1 and blurred in spondylodiscitis, is the most accurate sign to distinguish between Modic 1 and spondylodiscitis. Secondarily, the edema extent in the vertebral body and the T1 signal ratio (between edematous area and unaffected bone marrow) are considered as important features to distinguish the two entities [41]. A careful edema analysis reveals a mixed pattern of inflammation and fat in most cases of Modic lesions, contrary to spondylodiscitis [41]. This underlines the central role of the T1WI sequence to make the distinction between Modic lesions and spondylodiscitis with high accuracy. Pseudo-sparing [42], which refers to increased visibility of endplate contours, and the "ghost sign" [43], which refers to the reappearance of cortical bone on T1WI sequence after contrast injection, have also been described as being suggestive of infection. The extension of edema beyond the subchondral bone on fat-suppressed fluid-sensitive MRI images is an additional feature suggestive of infection rather than Modic 1, but this finding has been subject of controversy due to an overlap between infection and degenerative disorders [44]. A thin hypointense marrow between the disc and bone edema on STIR sequence may be present and reflects sclerosis, which is suggestive of Modic 1 rather than infection [45]. Regarding the disc signal, an absence of hyperintensity on T2WI is critical to make the diagnosis of Modic 1 [46]. Nevertheless, disc hypersignal is not specific of spondylodiscitis and could be related to a vacuum phenomenon in Modic changes due to disc disruption [41]. Even if no paravertebral abscess is visible, a very slight infiltration can be noticed. Concerning DWI, results of studies comparing ADC values between normal, degenerative, and 


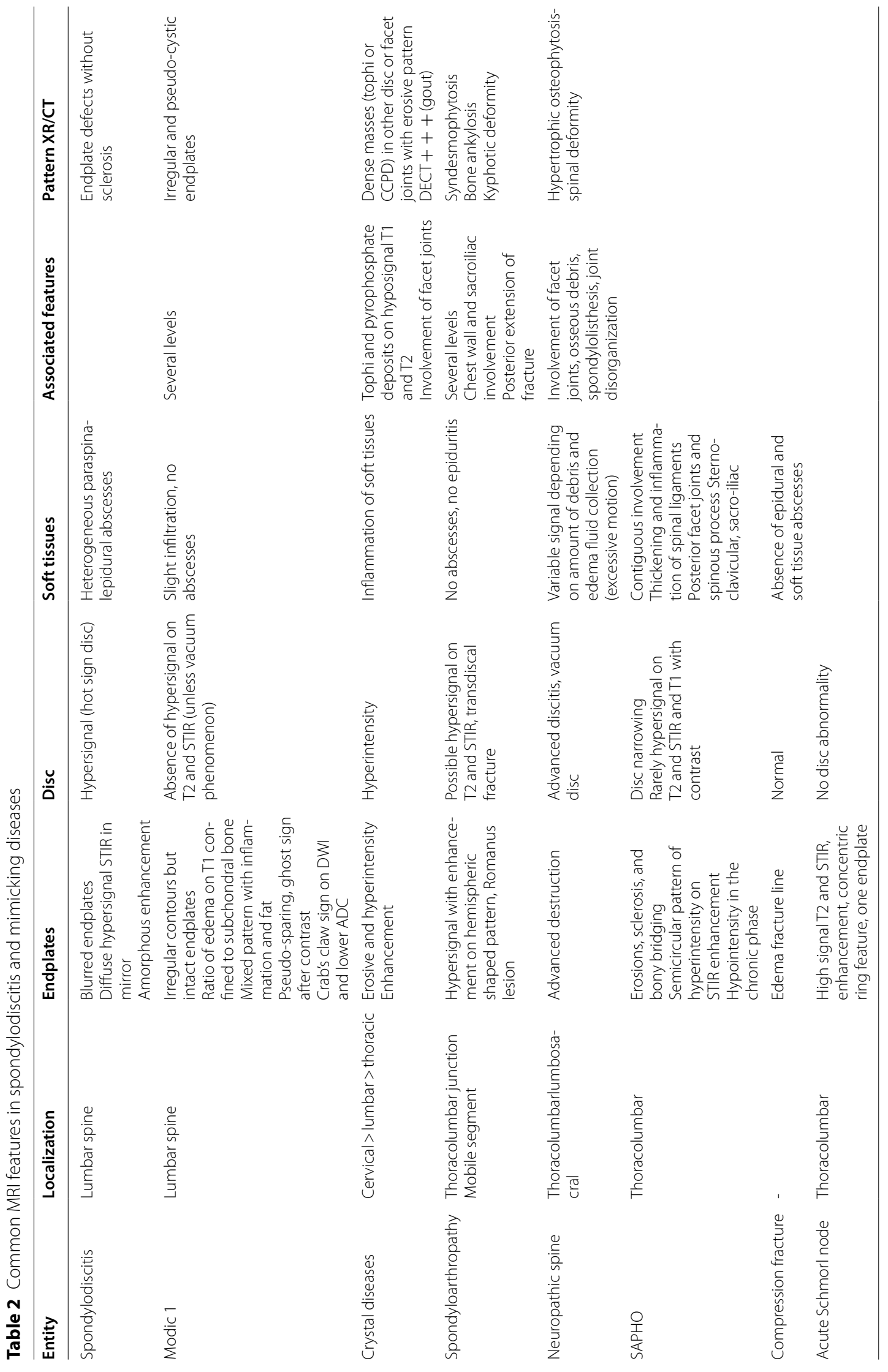




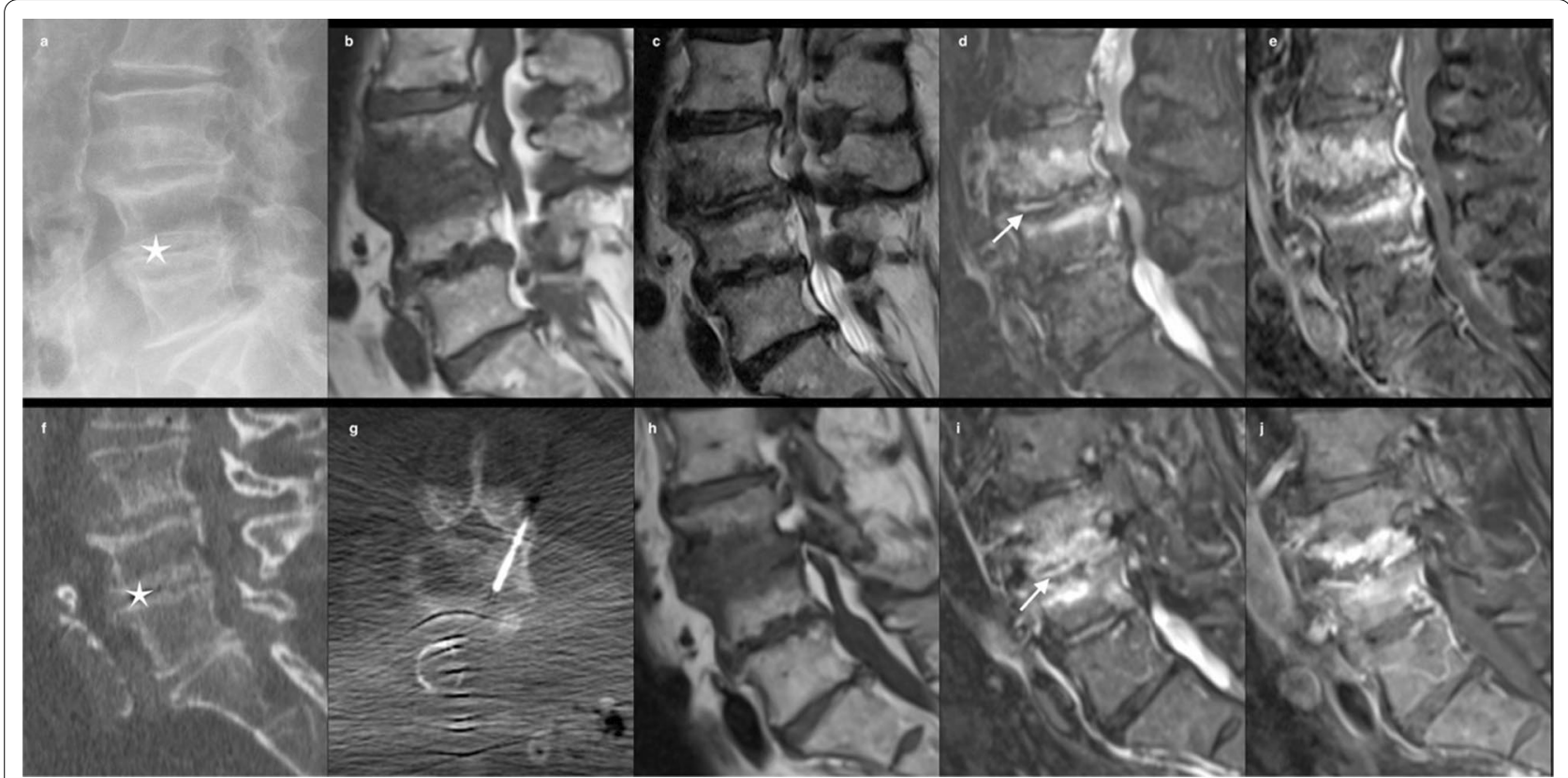

Fig. 1 68-year-old male with increasing back pain referred for pathologic confirmation and treatment of spondylodiscitis. Sagittal XR (a), Sagittal T1 (b), T2 (c), STIR (d) and T1 Fatsat after gadolinium R1 point 5 (e) confirm edema-type enhancing marrow signal abnormalities as well as disc hyperintensity (arrow), and narrowed L3-L4 space without disc enhancement. Following sagittal CT (f) R1 point 6 confirms the absence of endplates destruction and that the hypersignal on the underlying disc ( $L 4-L 5)$ corresponds to the vacuum phenomenon (star), biopsy performed under CT guidance (g) was negative. At 3 months, MRI control on sagittal T1 (h), STIR (i) and after contrast (j) shows stability of disco-vertebral features (arrow)

infectious diseases [47] demonstrated a lower ADC value $\left(1.12 \pm 0.22 \times 10^{-3} \mathrm{~mm}^{2} / \mathrm{s}\right)$ in degenerative diseases [13]. Furthermore, the extension and shape of abnormalities in the vertebral body can be characteristic on DWI and the "claw sign" [30], are suggestive of Modic 1 in opposition to an amorphous increased signal on DWI, which has been suggested to be a good indicator of infection [30].

\section{Andersson lesion in ankylosing spondylitis}

The Andersson lesion, which was first described by Andersson in 1937, is a rare but well-known destructive disco-vertebral complication of ankylosing spondylitis [48]. Though it is believed to be a late complication, many authors have reported it in the early stage of this rheumatoid disease. Its prevalence varies between 1.5 and $28 \%$ [49]. The disco-vertebral destruction is mediated by both inflammation and a micro-traumatic process, such as pseudarthrosis. Inflammation is accounted for by an acute enthesopathy [50], with an extension from anterior spondylitis to discs and endplates [51]. The micro-traumatic process, which is confirmed histologically by the presence of fibrosis and chondrodysplasia [52], occurs at the disc level [53]. Spondyloarthritis can affect one or several levels and predominates at the thoracolumbar junction [54-56]. Misdiagnosis with infectious discopathy, mainly in relation with tuberculosis in endemic areas, may lead to unnecessary investigations and costs [57]. Destructive and sclerotic changes on X-ray, CT, and MRI are frequent in chronic recurrent spondylitis and are known to be late features [53]. Discitis is possible, with narrowing and increased signal on T2WI and STIR, but no case of abscess or epiduritis has been reported in Andersson lesion. Endplate signal abnormalities appear as hypersignal on STIR and as hyposignal on T1WI, very often with a hemispheric-shaped pattern [53] (Fig. 2). While syndesmophytosis can be missed in these cases, it is highly suggestive of the disease and well detected by radiographs or CT, which additionally shows erosive and remodeled endplates with disc space narrowing [45]. Chest wall involvement and sacroiliac lesions are frequently associated [49]. MRI shows features of degenerative disease that mimic sclerotic Modic 3 [58]. Features of Romanus lesion are frequent, have to be detected in these cases, and also help to make the diagnosis [52]. Patients with spondyloarthropathy develop osteoporosis due to inflammation and kyphotic deformity (related to bone ankylosis) and they exhibit an increased risk of fractures at the thoracolumbar junction involving the "weak" segment, which is the disc. Hypertrophic nonunion is a well-known feature in this "mobile segment" and leads to 


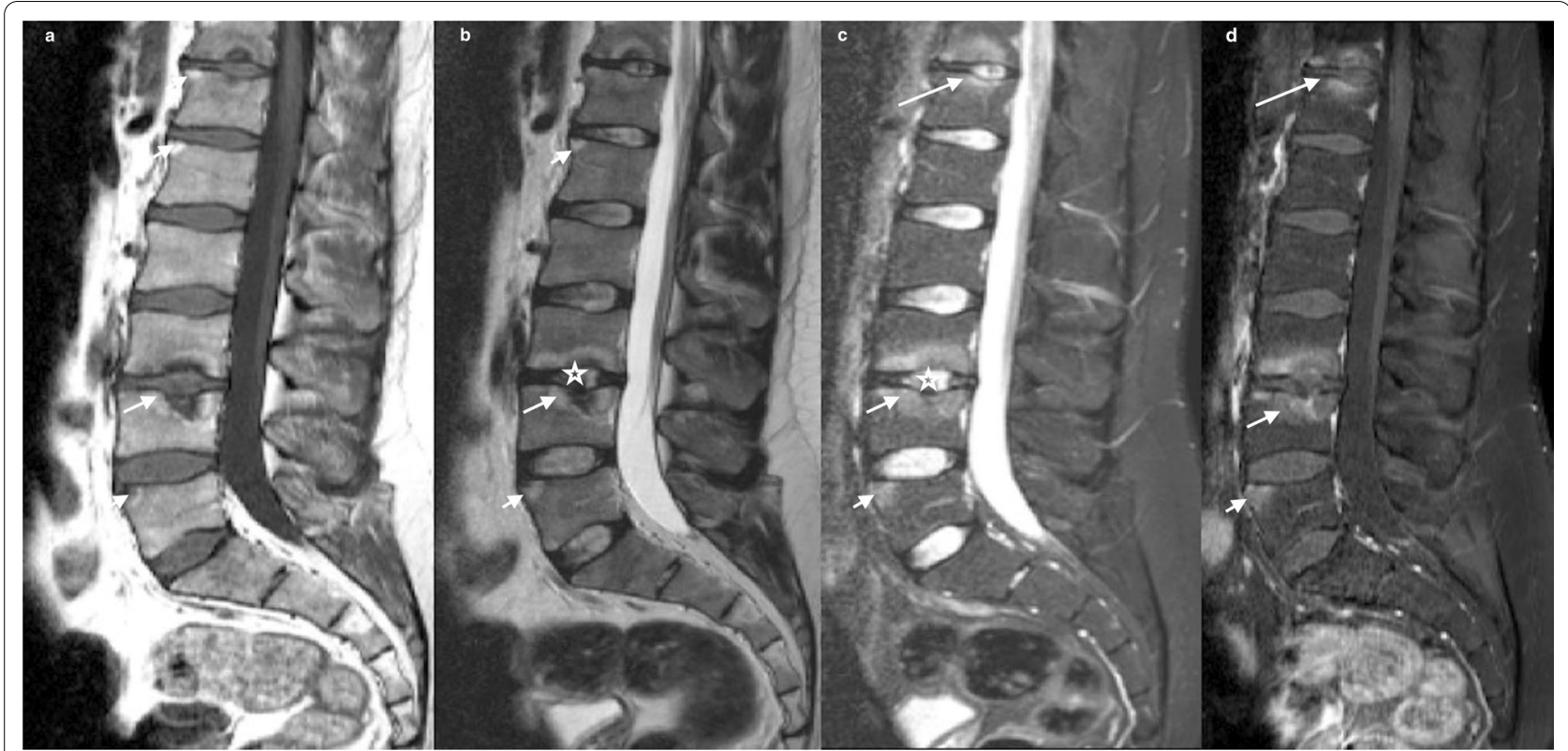

Fig. 2 32-year-old male admitted for exacerbation of back pain and inflammatory markers. T1 (a), T2WI (b), and STIR- R1 point 7 (c) show inflammatory endplate changes at the L3-L4 level mimicking a Schmorl node (arrow). Note that nuclear cleft sign is preserved (star). Enhancement in T1 fat-suppressed sequence after contrast (d) without disc enhancement or inflammatory paraspinal tissue. The same pattern is seen in the D11D12 disc space (long arrow), associated with Romanus feature R1 point 8 at L5 body margin (short arrow)

pseudarthrosis mimicking an erosive disco-vertebral disease, yet sclerosis and fracture visualization in the posterior column permit diagnosis [59] (Fig. 3).

\section{Crystal-induced discopathy}

Crystal deposition in the disc may mimic osteomyelitis in case of acute inflammatory presentation. Pathogenically, crystals form in the pericellular matrix of cartilage, thereby inducing inflammation and catabolic effects on chondrocytes and synoviocytes and resulting in pericellular matrix destruction; besides, metabolic deposits may accelerate joint damage [60]. The real prevalence of these spinal disorders is unknown and probably underestimated [61, 62], mainly because of an increasing incidence in the elderly population $[63,64]$. Only case reports are available in the literature $[65,66]$. Crystal diseases predominate in males, with a wide range of age (median of 59 years for gout) [61]. In most cases, a prior history of crystal disease is known. However, the prevalence of presentation as "spondylodiscitis" has not been reported in the published series. While the cervical spine is usually affected, the lumbar spine may also be involved in rare cases; though rare, gout is the most frequent crystalinduced discopathy $[63,67,68]$. R1Point 4 Toprover et al. reported the largest series including 133 cases of spinal gout [61], which exhibits the clinical characteristics of arthritis [69]. Calcium pyrophosphate deposition (CPPD) disease causes an acute inflammation by mass effect [63,
67]. It predominates in the cervical spine (crowned dens syndrome), followed by the lumbar and rarely the thoracic spine [70]. In the majority of cases, disco-vertebral biopsies are negative and MRI features are misdiagnosed as an infection. MRI is the most used modality, being pathologic in more than $90 \%$ of cases, but without specific findings. An erosive pattern in adjacent vertebral plates is frequent, along with an increased signal in the disc and surrounding soft tissues. Tophi or CPPD appear hypo- or isointense compared to muscles on $\mathrm{T} 1$ and T2WI with peripheral enhancement [69, 71, 72] (Fig. 4). Hence, these signal abnormalities help to make the diagnosis, although signal may be hyperintense even on T1 or T2WI. Tophi or CPPD can usually be visualized on radiographs and especially on CT, yet not in all cases, and the most common findings are joint erosions associated to dense masses [73, 74]. Performing both a CT scan to detect crystal deposition at other disc levels or in posterior joints and to show sclerotic margins and surrounding dense masses in case of gout and an aspiration or biopsy is key to diagnosis. The recent development of spectral imaging, such as DECT, is promising to detect monosodium urate crystal deposition and thus allow differentiation between several materials $[75,76]$, without further need of percutaneous or surgical biopsies. The final diagnosis can be made using routine polarized light microscopy, which reveals negatively birefringent urate crystals in case of gout or calcium pyrophosphate 


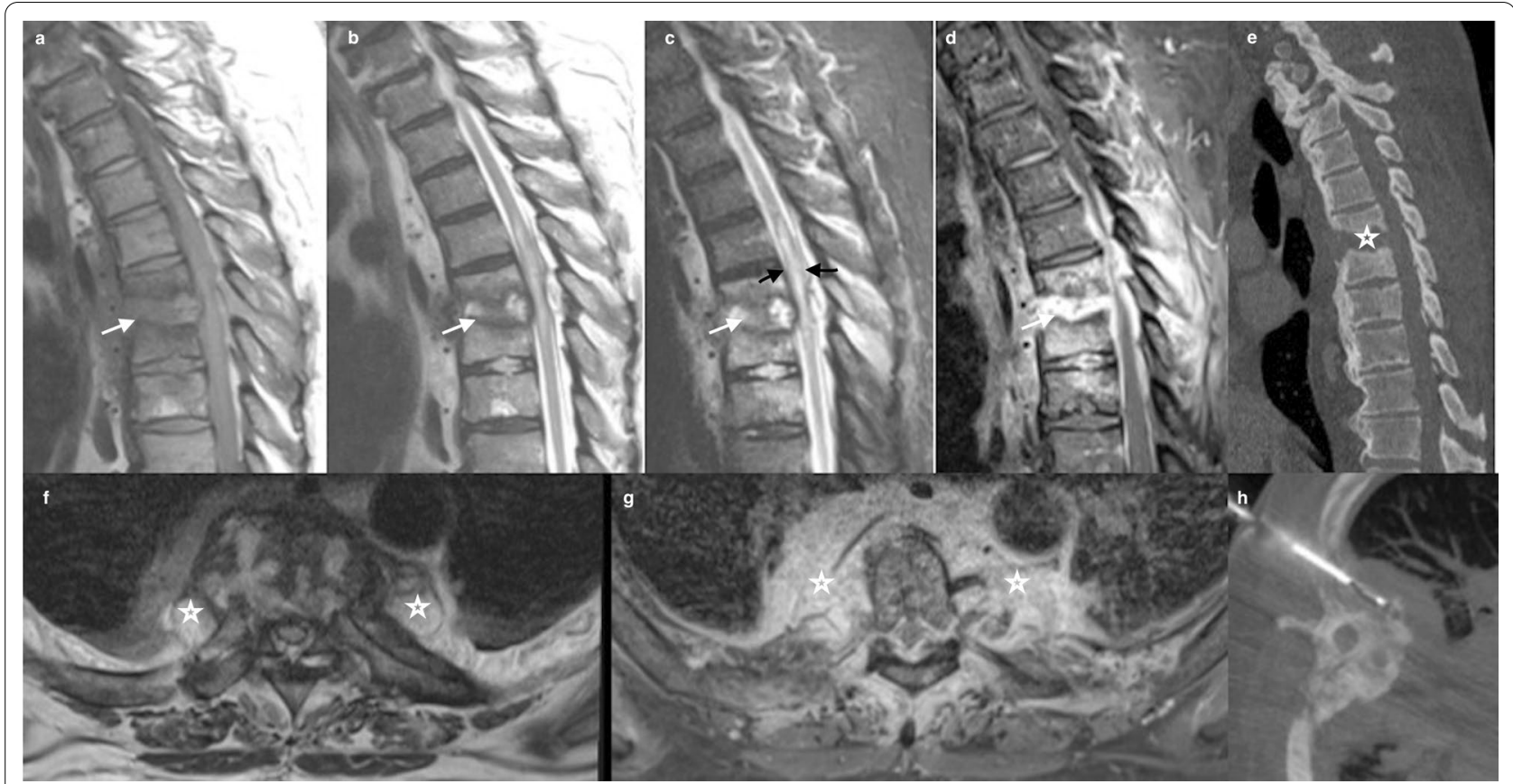

Fig. 3 R1 point 9: 78-year-old male with sepsis and thoracic back pain with ankylosing spondylitis. MRI (sagittal T1 (a), T2 (b), STIR (c) and T1 Fat Sat Gadolinium (d)) shows T6-T7 disc hypersignal, enhanced after administration of contrast (arrow) and marked inflammatory surrounding tissue in axial T2 (f) and axial T1FS with contrast (g) (star). Note the elevated medullary signal intensity secondary to compression (black arrow). Reformatted $\mathrm{CT}$ (e) shows ankylosed spine and transdiscal fracture (star). Discal biopsy (h) was performed to exclude an infection R1 point 10. Andersson discitis was diagnosed

dihydrate crystals in case of chondrocalcinosis (pseudogout). Crystal diseases with no neurological emergency can effectively be managed using a conservative treatment (anti-inflammatory prophylaxis and urate-lowering therapy).

\section{Neuropathic spinal arthropathy}

Also known as Charcot spine, this condition is characterized by a rapid destruction of disco-vertebral and facet joints due to several neuropathic disorders [77]. The underlying mechanism is a loss of protective sensation and proprioceptive reflexes [78]. Delay in diagnosis is the rule, in addition to non-specific imaging features. Spinal cord traumatic injury is the most common underlying condition affecting the mobile segments above or below the stabilized one [79]. Hence, the thoraco-lumbar and lumbosacral segments are most commonly involved. The atrophic form of this disease is characterized by bone resorption and may mimic septic arthropathy. Thus, spondylodiscitis is the main differential diagnosis. MRI is best suited for differentiation using morphological and functional sequences [80]. MRI shows an advanced destruction of endplates and discs as well as an involvement of facet joints, which are rarely associated in spondylodiscitis [77]. Disco-vertebral destruction is usually accompanied by hypertrophic osteophytosis and spinal deformity [81]. Soft tissue masses are typically hypointense on T1WI and isointense to hyperintense on T2WI, depending on bone debris and variable amount of edema (Fig. 5). An associated fluid collection due to excessive motion is characteristic of this disease during the atrophic phase [78]. The main features allowing distinction between neuropathic spinal arthropathy and spondylodiscitis include vacuum disc phenomenon, osseous debris, spondylolisthesis, and joint disorganization [82, 83]. Of note, secondary infections have been observed in $17 \%$ of cases [84]. The imaging features of neuropathic spinal arthropathy are classically described as the six D's, standing for: Distension (for soft tissue mass), Density (for sclerosis), Debris (for bone fragmentation), Disorganization (for joint dislocation), Destruction (for endplate and facet erosions), and Dislocation (for spondylolisthesis) [85].

\section{Synovitis, acne, pustulosis, hyperostosis, osteitis (SAPHO) syndrome}

Spinal involvement is the second most frequent manifestation of the synovitis, acne, pustulosis, hyperostosis, osteitis (SAPHO) syndrome [86], with thoraco-lumbar segments being most commonly affected [87]. It is 

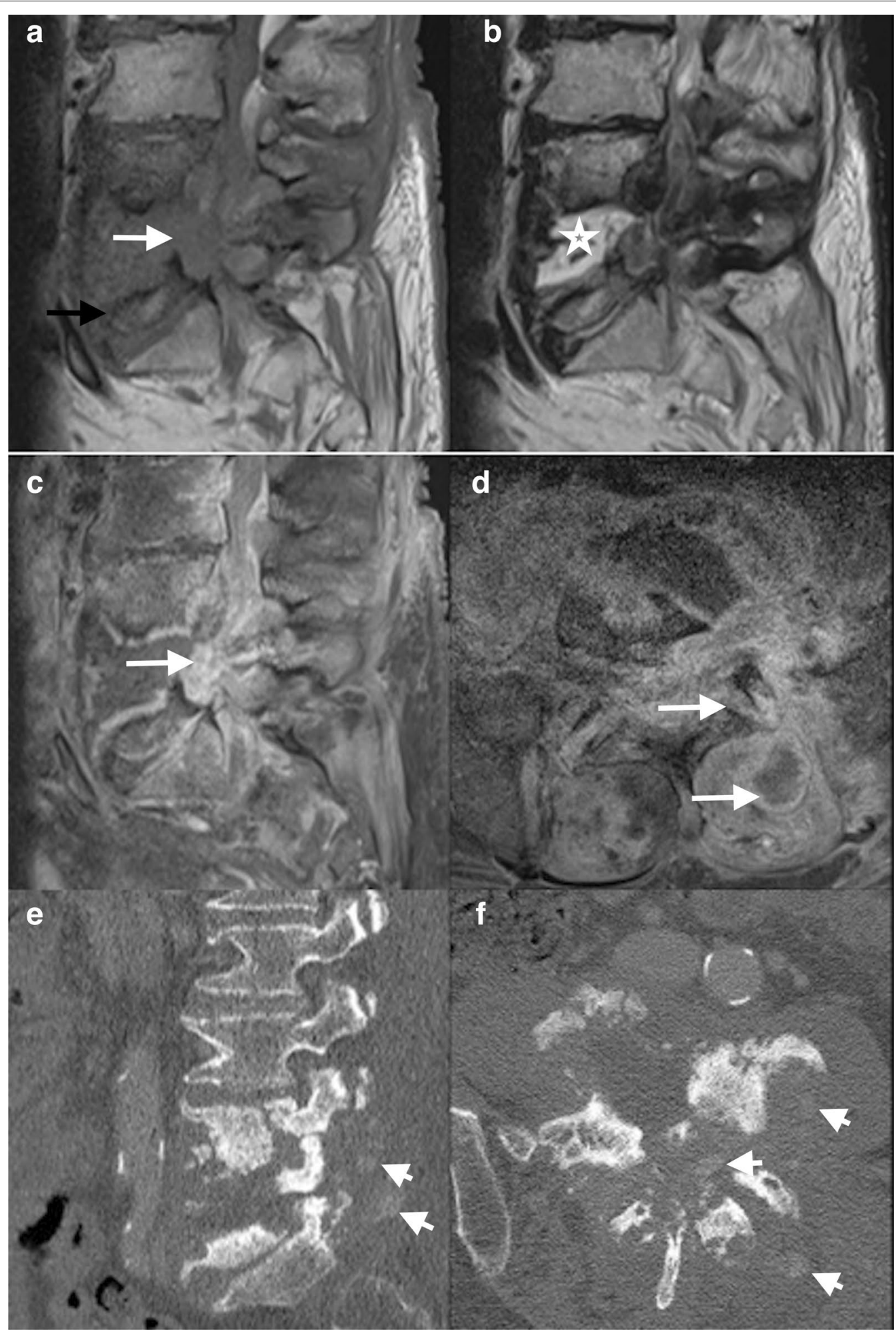

Fig. 4 70-year-old male with chronic history of back pain, recently exacerbated, and inflammatory laboratory markers. Sagittal T1WI (a) shows hypointense discal changes in the L4-L5 space and epidural space (arrow). Bony erosion of endplates is also seen (black arrow) at the L5 level (b c). Sagittal T2WI (b) shows hyperintense areas in the L4-L5 disc space (star). Contrast-enhanced sagittal and axial T1WI (c, d) show enhancement of disc space, epidural space, left facet joint, and paraspinal muscles (arrow). Non-enhancing foci correspond to crystal material (arrow). Axial and sagittal slices of CT (e, f) show in L4-L5, disc space erosions, sclerotic vertebral bodies, and confirm gout tophi in muscles (short arrow) 


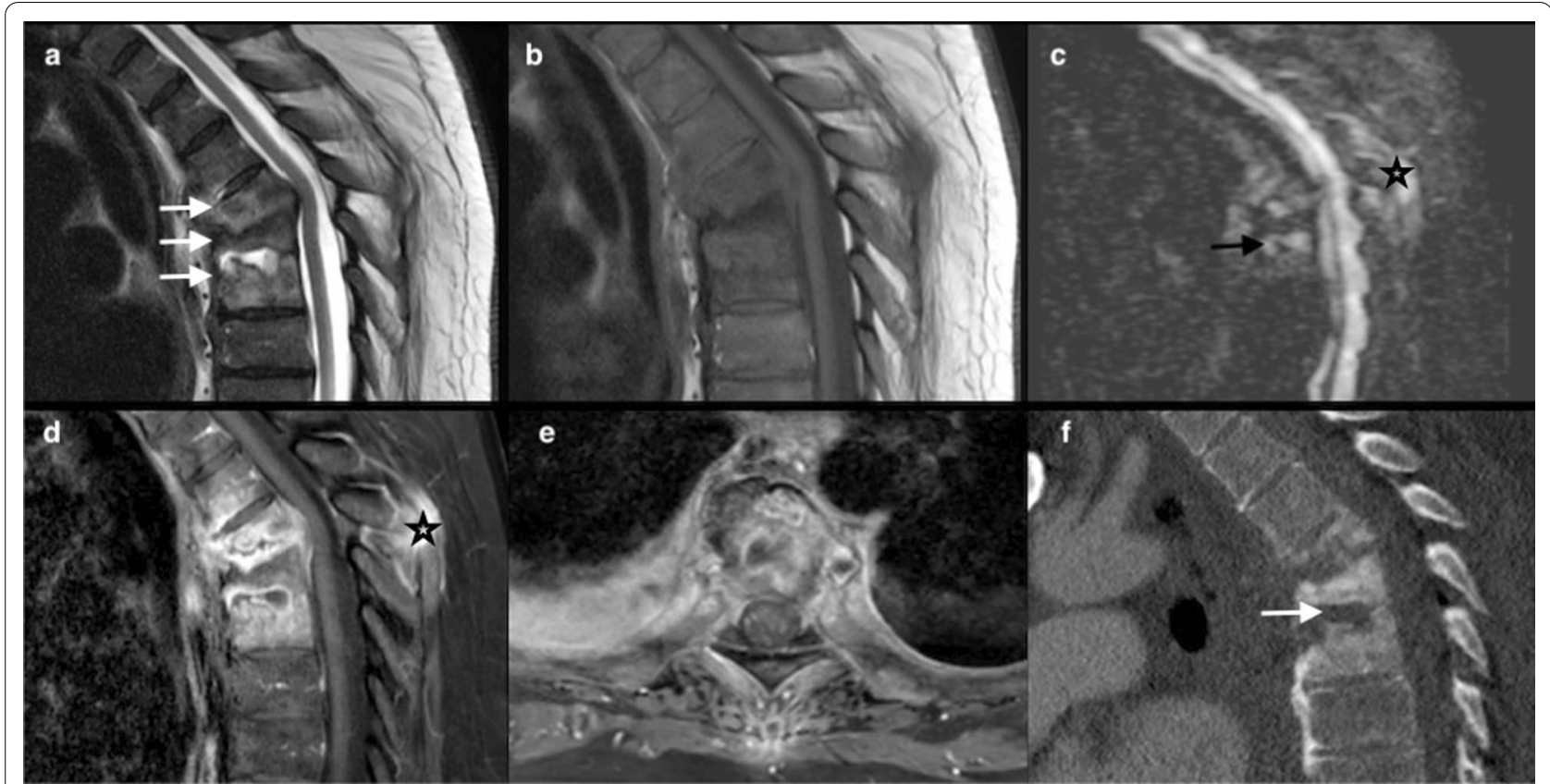

Fig. 5 72-year old male with amyotrophic lateral sclerosis presenting with subacute back pain, fever and inflammation in laboratory findings. Sagittal T2 (a), T1 (b) WI, DWI (c) and T1 after contrast on sagittal (d) and axial planes (e) show multiple contiguous erosive disco-vertebral disease on dorsal spine with local deformity and advanced destruction (arrow). No diffusion restriction was noticed on DWI (black arrow). Note anterior and posterior involvement (star). Reformatted sagittal CT (f) shows bone sclerosis and subtle vacuum phenomena in the disc (arrow). R1 Point 11 The final diagnosis was Charcot spine

characterized by vertebral endplate erosions, subchondral sclerosis, and bony bridging. These abnormalities predominate on the anterior side of the vertebra, although posterior facet joints and spinous process are also frequently affected. Contiguous involvement is frequent, being observed in up to $89 \%$ of cases [88]. Abnormalities are described as having a semicircular pattern (Fig. 6). In the active phase, MRI shows the bone marrow edema as hypointense on T1WI and as hyperintense on T2, STIR, and T1WI following contrast injection. Moreover, it detects the surrounding soft tissue inflammation. Soft tissue mass is due to thickening and inflammation of spinal ligaments [89]. In cases of SAPHO syndrome, disc narrowing is frequent, but hypersignal and enhancement after contrast injection are very rare (11\%) [88], yet they have been described by some authors [90]. These findings may mimic spondylodiscitis, while sterile spondylodiscitis has been described in 9 to $32 \%$ of SAPHO syndrome cases [91]. An association with hypointensities in the chronic phase and the involvement of other sites (e.g., sterno-clavicular and sacro-iliac findings) help to make the diagnosis. Whole-body MRI offers the possibility to explore all affected sites besides the spine [92].

\section{Miscellaneous}

Disc disorders associated with vertebral fractures

Vertebral compression fractures may mimic spondylodiscitis, mostly tuberculous spondylitis, if the endplate is poorly defined in the absence of an obvious trauma history [93]. MRI shows bone marrow edema and allows ruling out a discitis. The lack of epidural extension and paraspinal mass enables to make the diagnosis. Finally, vertebral fractures may complicate mycobacterial infections or pyogenic spondylitis at an early stage [94].

\section{Acute schmorl nodes}

Schmorl nodes represent an extrusion of a disc through an endplate around the cartilaginous node. They manifest as high signal intensity on T2WI and STIR and low signal intensity on T1WI and contrast enhancement, with a correlation with pain in some cases. The concentric ring feature and involvement of an endplate without signal intensity abnormalities allow ruling out the diagnosis of spondylodiscitis [95].

\section{Conclusion}

Although MRI features of disco-vertebral infections are usually quite typical, there are a variety of degenerative, post-traumatic, metabolic, and non-infectious 


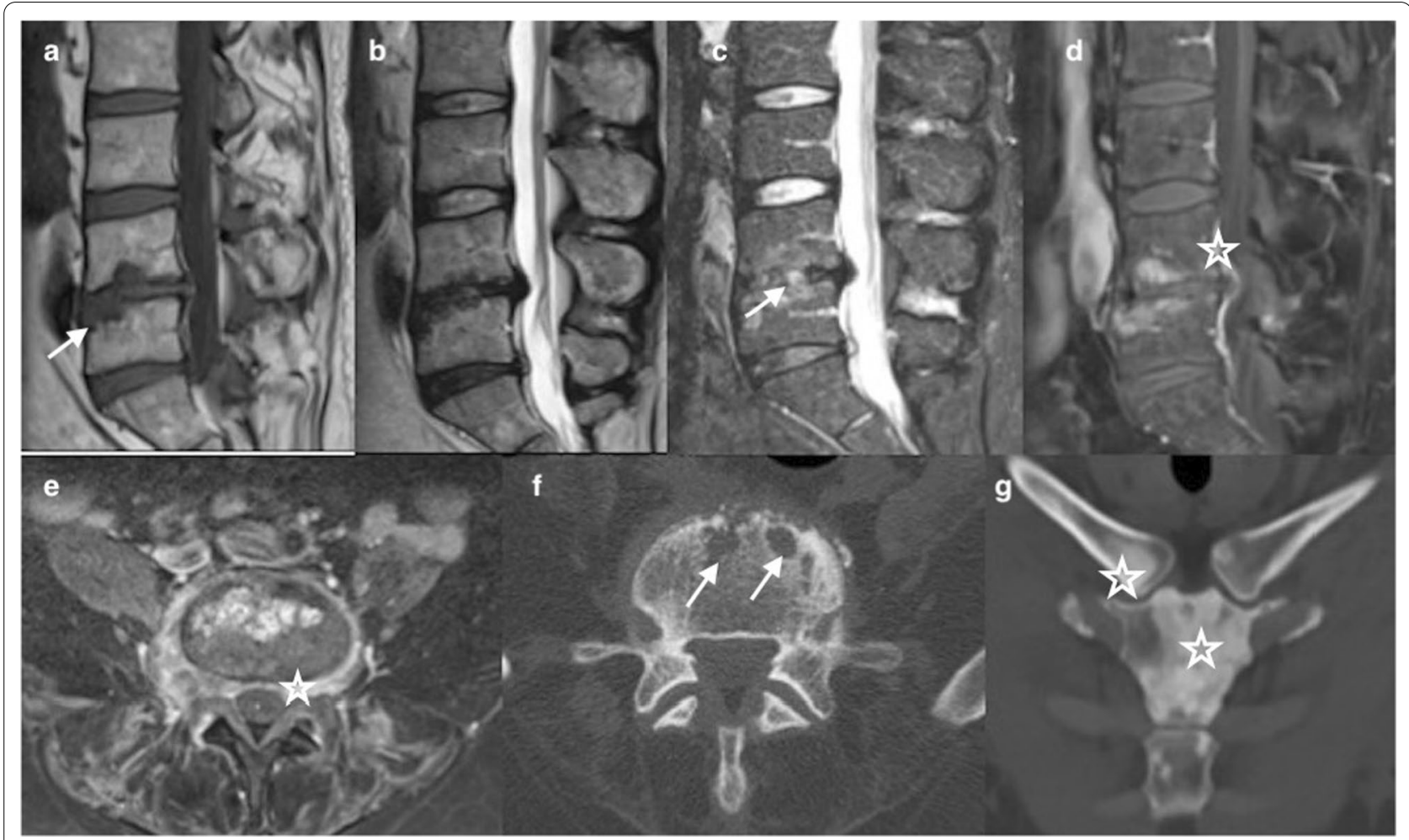

Fig. 6 47-year-old male presenting with inflammatory back pain. Sagittal T1 (a) and R1 point 12T2 (b)-WI show erosive L4-L5 endplates (arrow) associated on Sagittal STIR sequence (c) to a disc hypersignal (arrow) and on sagittal (d) and axial (e) T1 Fat Sat WI enhanced sequences to an enhancement of vertebral bodies and surrounding tissues as epidural fat space without abscess (star). Axial CT (f) on lumbar spine shows erosive pattern of vertebra (arrow) and Oblique reformatted CT (g) of anterior chest shows involvement with sclerotic lesions typical of SAPHO disease (star)

inflammatory conditions that may present with similar features. Awareness of the differential diagnoses described above and knowledge of the specific pattern on MRI may help the radiologist to avoid these pitfalls and an unnecessary disco-vertebral biopsy.

\section{Abbreviations \\ ${ }^{18}$ F-FDG: 18F-fluorodeoxyglucose; ADC: Apparent diffusion coefficient; CRP: C reactive protein; $\mathrm{CT}$ : Computed tomography; DECT: Dual-energy computed tomography; DWI: Diffusion weighted imaging; MRI: Magnetic resonance imaging; SAPHO: Synovitis, Acne, Pustulosis, Hyperostosis and Osteitis; SPD: Spondylodiscitis; STIR: Short tau inversion recovery; T:Tesla.}

\section{Acknowledgements}

We thank Dr Gabrielle Cremer Consulting for English linguistic editing: https:// www.cremerconsulting.com/fr/.

\section{Authors' contributions}

Guarantor of integrity of the entire review (SB and MIV), Study concepts and design (SB, ENP, MH, MIV), Literature research (SB, ENP, MIV), Manuscript preparation (SB, EN, MH, BMAD, MIV), Technical aspect (BMAD), Manuscript editing (SB, EN, MH, BMAD, MIV). All authors read and approved the final manuscript.

\section{Funding}

Not applicable.

\section{Availability of data and materials}

The datasets used and/or analyzed during the current study are available from the corresponding author on reasonable request.

\section{Declarations}

Ethics approval and consent to participate

All procedures performed in studies involving human participants were in accordance with the ethical standards of Geneva University institutional review board.

\section{Consent for publication}

Not applicable.

\section{Competing interests}

The authors declare that they have no competing interests.

\section{Author details}

'Division of Radiology, Department of Diagnosis, Geneva University Hospitals, Rue Gabrielle-Perret-Gentil 4, 1211 Geneva 14, Switzerland. ${ }^{2}$ Faculty of Medicine of the Geneva University, Geneva, Switzerland. ${ }^{3}$ Division of Radiology, Medical Imaging Department, Hospital of Neuchatel, Neuchâtel, Switzerland. ${ }^{4}$ Division of Neuroradiology, Diagnostic Department, University Hospitals of Geneva, Geneva, Switzerland.

Received: 10 August 2021 Accepted: 3 October 2021

Published online: 04 December 2021 


\section{References}

1. Braun A, Germann T, Wünnemann F et al (2019) Impact of MRI, CT, and clinical characteristics on microbial pathogen detection using CT-guided biopsy for suspected spondylodiscitis. J Clin Med 9(1):32-43

2. Petkova AS, Zhelyazkov CB, Kitov BD (2017) Spontaneous. Spondylodiscitis epidemiology, clinical features, diagnosis and treatment. Folia Med 59(3):254-260

3. Butler JS, Shelly MJ, Timlin M, Powderly WG, O'Byrne JM (2006) Nontuberculous pyogenic spinal infection in adults: a 12-year experience from a tertiary referral center. Spine (Phila Pa 1976) 31(23):2695-2700

4. Ahuja N, Sharma H (2017) The effectiveness of computed tomographyguided biopsy for the diagnosis of spondylodiscitis: an analysis of variables affecting the outcome. Eur Rev Med Pharmacol Sci 21(9):2021-2026

5. Zarghooni K, Röllinghoff M, Sobottke R, Eysel P (2012) Treatment of spondylodiscitis. Int Orthop 36(2):405-411

6. Mylona E, Samarkos M, Kakalou E, Fanourgiakis P, Skoutelis A (2009) Pyogenic vertebral osteomyelitis: a systematic review of clinical characteristics. Semin Arthr Rheum 39:10-17

7. R1 Point 1 7. Saifuddin A, Palloni V, du Preez H, Junaid SE (2021) The current status of CT-guided needle biopsy of the spine. Skeletal Radiol 50(2):281-299

8. R1 Point 1 8. Rimondi E, Staals EL, Errani C et al (2008) Percutaneous CT-guided biopsy of the spine: results of 430 biopsies. Eur Spine $J$ 17(7):975-981.

9. R1 Point 1 9. Huang AJ, Halpern EF, Rosenthal DI (2013). Incidence of delayed complications following percutaneous CT-guided biopsy of bone and soft tissue lesions of the spine and extremities: a 2-year prospective study and analysis of risk factors. Skeletal Radiol 42(1):61-68.

10. Michel SCA, Pfirrmann CWA, Boos N, Hodler J (2006) CT-guided core biopsy of subchondral bone and intervertebral space in suspected spondylodiskitis. AJR Am J Roentgenol 186(4):977-980

11. Rieneck K, Hansen SE, Gutschik AKE (1996) Microbiologically verified diagnosis of infectious spondylitis using CT-guided fine needle biopsy. APMIS 104(10):755-762

12. Herren C, Jung N, Pishnamaz M, Breuninger M, Siewe J, Sobottke R (2017) Spondylodiscitis: diagnosis and treatment options. Dtsch Arztebl Int 114(51-52):875-882

13. Chen TY, Wu TC, Tsui YK (2015) Diffusion-weighted magnetic resonance imaging and apparent diffusion coefficient mapping for diagnosing infectious spondylodiscitis: a preliminary study. J Neuroimaging 25(3):482-487

14. Daghighi MH, Poureisa M, Safarpour M et al (2016) Diffusion-weighted magnetic resonance imaging in differentiating acute infectious spondylitis from degenerative Modic type 1 change; the role of b-value, apparent diffusion coefficient, claw sign and amorphous increased signal. $\mathrm{Br} J$ Radiol 89(1066):20150152

15. Oztekin O, Calli C, Kitis O et al (2010) Reliability of diffusion weighted MR imaging in differentiating degenerative and infectious end plate changes. Radiol Oncol 44(2):97-102

16. Balliu E, Vilanova JC, Peláez I et al (2009) Diagnostic value of apparent diffusion coefficients to differentiate benign from malignant vertebral bone marrow lesions. Eur J Radiol 69(3):560-566

17. Baur A, Dietrich O, Reiser M (2003) Diffusion-weighted imaging of bone marrow: current status. Eur Radiol 13(7):1699-1708

18. Balasubramanya R, Selvarajan SK (2021) Lumbar spine imaging. StatPearls Publishing, Treasure Island

19. Johnson TR (2012) Dual-energy CT: general principles. AJR Am J Roentgenol 199(5 Suppl):S3-S8

20. Booz C, Nöske J, Martin SS et al (2019) Virtual noncalcium dual-energy CT: detection of lumbar disk herniation in comparison with standard grayscale CT. Radiology 290(2):446-455

21. Ogdie A, Taylor WJ, Weatherall M et al (2015) Imaging modalities for the classification of gout: systematic literature review and meta-analysis. Ann Rheum Dis 74:1868-1874

22. Raghavan M, Lazzeri E, Palestro CJ (2018) Imaging of spondylodiscitis. Semin Nucl Med 48(2):131-147

23. Altini C, Lavelli V, Niccoli-Asabella A et al (2020) Comparison of the diagnostic value of MRI and whole body ${ }^{18} \mathrm{~F}-\mathrm{FDG}$ PET/CT in diagnosis of spondylodiscitis. J Clin Med 9(5):1581

24. Leone A, Dell'atti C, Magarelli N et al (2012) Imaging of spondylodiscitis. Eur Rev Med Pharmacol Sci 16:8-19
25. Lazzeri E, Bozzao A Cataldo MA et al (2019) Joint EANM/ESNR and ESC MID-endorsed consensus document for the diagnosis of spine infection (spondylodiscitis) in adults. Eur J Nucl Med Mol Imaging 46:2464-2487

26. Ledermann HP, Schweitzer ME, Morrison WB, Carrino JA (2003) MR imaging findings in spinal infections: rules or myths? Radiology 228(2):506-514

27. R1 Point 3 27. Sathekge MM, Ankrah AO, Lawal I, Vorster M (2018) Monitoring response to therapy. Semin Nucl Med 48(2):166-181

28. R1 Point 3 28. Righi E, Carnelutti A, Muser D et al (2020) Incremental value of FDG-PET/CT to monitor treatment response in infectious spondylodiscitis. Skeletal Radiol 49(6):903-912

29. Kwon JW, Hyun SJ, Han SH, Kim KJ, Jahng TA (2017) Pyogenic vertebral osteomyelitis: clinical features, diagnosis, and treatment. Korean J Spine 14(2):27-34

30. Patel KB, Poplawski MM, Pawha PS, Naidich TP, Tanenbaum LN (2014) Diffusion-weighted MRI "claw sign" improves differentiation of infectious from degenerative modic type 1 signal changes of the spine. AJNR Am J Neuroradiol 35(8):1647-1652

31. Drake-Pérez M, Delattre BMA, Boto J et al (2018) Normal values of magnetic relaxation parameters of spine components with the synthetic MRI sequence. AJNR Am J Neuroradiol 39(4):788-795

32. Foreman SC, Schwaiger BJ, Gempt J et al (2017) MR and CT imaging to optimize CT-guided biopsies in suspected spondylodiscitis. World Neurosurg 99:726-734

33. Modic MT, Steinberg PM, Ross JS, Masaryk TJ, Carter JR (1988) Degenerative disk disease: assessment of changes in vertebral body marrow with MR imaging. Radiology 166(1 Pt 1):193-199

34. Nguyen C, Poiraudeau S, Rannou F (2015) From Modic 1 vertebral-endplate subchondral bone signal changes detected by MRI to the concept of 'active discopathy. Ann Rheum Dis 74(8):1488-1494

35. Huang ZY, Xu HC, Lei T, Li QL, Wu AM, Ni WF (2016) The location of Modic changes in the lumbar spine: a meta-analysis. Eur Spine J 25(11):3746-3759

36. Rausch VH, Bannas P, Schoen G et al (2017) Diagnostic yield of multidetector computed tomography in patients with acute spondylodiscitis. Rofo 189(4):339-346

37. Schwarz-Nemec U, Friedrich KM, Stihsen C et al (2020) Vertebral bone marrow and endplate assessment on MR imaging for the differentiation of modic type 1 endplate changes and infectious spondylodiscitis. J Clin Med 9(3):826

38. R1 Point 2 38. Strauss SB, Gordon SR, Burns J, Bello JA, Slasky SE (2020) Differentiation between tuberculous and pyogenic spondylodiscitis: the role of the anterior meningovertebral ligament in patients with anterior epidural abscess. AJNR Am J Neuroradiol 41(2):364-368

39. R1 Point 2 39. Boody BS, Tarazona DA, Vaccaro AR (2018) Evaluation and management of pyogenic and tubercular spine infections. Curr Rev Musculoskelet Med 11(4):643-652

40. R1 Point 2 40. Yangwon L, Bum-Joon K, Se-Hoon K (2018) Comparative analysis of spontaneous infectious spondylitis: pyogenic versus tuberculous. J Korean Neurosurg Soc 61(1):81-88

41. R1 Point 2 41. Homagk L, Marmelstein D, Homagk N (2019) SponDT spondylodiscitis diagnosis and treatment): spondylodiscitis scoring system. J Orthop Surg Res 14(1):100

42. Wolansky LJ, Heary RF, Patterson T et al (1999) Pseudosparing of the endplate: a potential pitfall in using MR imaging to diagnose infectious spondylitis. AJR Am J Roentgenol 172:777-780

43. Donovan A, Schweitzer ME (2010) Use of MR imaging in diagnosing diabetes-related pedal osteomyelitis. Radiographics 30:723-736

44. Shrot S, Sayah A, Berkowitz F (2017) Can the pattern of vertebral marrow oedema differentiate intervertebral disc infection from degenerative changes? Clin Radiol 72:e7-e613

45. Kuisma M, Karppinen J, Haapea M, Lammentausta E, Niinimäki J, Tervonen O (2009) Modic changes in vertebral endplates: a comparison of MR imaging and multislice CT. Skeletal Radiol 38(2):141-147

46. Kumar Y, Gupta N, Chhabra A, Fukuda T, Soni N, Hayashi D (2017) Magnetic resonance imaging of bacterial and tuberculous spondylodiscitis with associated complications and non-infectious spinal pathology mimicking infections: a pictorial review. BMC Musculoskelet Disord 18:244

47. Eguchi Y, Ohtori S, Yamashita M et al (2011) Diffusion magnetic resonance imaging to differentiate degenerative from infectious endplate abnormalities in the lumbar spine. Spine (Phila Pa 1976) 36(3):E198-202 
48. Andersson O (1937) Röntgenbilden vid spondylarthritis ankylopoetica. Nord Med Tidskr 14:2000-2002

49. Aes A, Abd El-Hamid HI (2016) Spondylodiscitis disease evaluation in patinets with seronegative spondylarthropathies. J Egypt Soc Parasitol 46(3):655-662

50. Rasker JJ, Prevo RL, Lanting PJ (1996) Spondylodiscitis in ankylosing spondylitis, inflammation or trauma? A description of six cases. Scand J Rheumatol 25(1):52-57

51. Courtois C, Fallet GH, Vischer TL, Wettstein P (1980) Erosive spondylopathy. Ann Rheum Dis 39(5):462-468

52. Park YS, Kim JH, Ryu JA, Kim TH (2011) The Andersson lesion in ankylosing spondylitis: distinguishing between the inflammatory and traumatic subtypes. J Bone Joint Surg Br 93(7):961-966

53. Hermann KG, Althoff CE, Schneider U et al (2005) Spinal changes in patients with spondyloarthritis: comparison of MR imaging and radiographic appearances. Radiographics 25(3):559-569

54. Dave BR, Ram H, Krishnan A (2011) Andersson lesion: are we misdiagnosing it? A retrospective study of clinico-radiological features and outcome of short segment fixation. Eur Spine J 20(9):1503-1509

55. Baraliakos $X$, Landewé $R$, Hermann KG et al (2005) Inflammation in ankylosing spondylitis: a systematic description of the extent and frequency of acute spinal changes using magnetic resonance imaging. Ann Rheum Dis 64(5):730-734

56. Braun J, Golder W, Bollow M et al (2002) Imaging and scoring in ankylosing spondylitis. Clin Exp Rheumatol 20(6 Suppl 28):S178-S184

57. Dhakad U, Das SK (2013) Andersson lesion in ankylosing spondylitis. Case Rep. https://doi.org/10.1136/bcr-2012-008404

58. Jevtic V, Kos-Golja M, Blaz R, McCall I (2000) Marginal erosive discovertebral "Romanus" lesions in ankylosing spondylitis demonstrated by contrast enhanced Gd-DTPA magnetic resonance imaging. Skeletal Radiol 29(1):27-33

59. Johannes LB, Vries MK, Snieders MN, van der Horst-Bruinsma IE, Van Royen BJ (2009) Discovertebral (Andersson) lesions of the spine in ankylosing spondylitis revisited. Clin Rheumatol 28(8):883-892

60. Kelly J, Lim C, Kamel M, Keohane C, O'Sullivan M (2005) Topacheous gout as a rare cause of spinal stenosis in the lumbar region. Case Report. J Neurosurg Spine 2(2):215-217

61. Toprover M, Krasnokutsky S, Pillinger MH (2015) Gout in the spine: imaging, diagnosis, and outcomes. Curr Rheumatol Rep 17(12):70

62. Hou LC, Hsu AR, Veeravagu A, Boakye M (2007) Spinal gout in a renal transplant patient: a case report and literature review. Surg Neurol 67(1):65-73

63. Mahmud T, Basu D, Dyson PHP (2005) Crystal arthropathy of the lumbar spine: a series of six cases and a review of the literature. Bone Joint Surg Br 87(4):513-517

64. Bartlett CS, Casden AM, Abdelwahab IF (1999) Calcium pyrophosphate deposition disease mimicking infection in the lumbar spine. Orthopedics 22(1):79-81

65. Mikhael MM, Chioffe MA, Shapiro GS (2013) Calcium pyrophosphate dihydrate crystal deposition disease (pseudogout) of lumbar spine mimicking osteomyelitis-discitis with epidural phlegmon. Am J Orthop 42(8):E64-E67

66. Grobost V, Vayssade M, Roche A, Kemeny JL, Soubrier M (2014) Axial calcium pyrophosphate dihydrate deposition disease revealed by recurrent sterile spondylodiscitis and epidural abscess. Joint Bone Spine 81(2):180-182

67. Baty V, Prost B, Jouvet A, Laurent J, Vallée B (2003) Acute spinal cord compression and calcium pyrophosphate deposition disease. Case illustration J Neurosurg 99(2 Suppl):240

68. Rosenthal AK, Ryan LM (2016) Calcium pyrophosphate deposition disease. N Engl J Med 374(26):2575-2584

69. Bonaldi VM, Duong H, Starr MR, Sarazin L, Richardson J (1996) Tophaceous gout of the lumbar spine mimicking an epidural abscess: MR features. AJNR Am J Neuroradiol 17(10):1949-1952

70. Salcman M, Khan A, Symonds DA (1994) Calcium pyrophosphate arthropathy of the spine: case report and review of the literature. Neurosurgery 34(5):915-918

71. Thornton FJ, Torreggiani WC, Brennan P (2000) Tophaceous gout of the lumbar spine in a renal transplant patient: a case report and literature review. Eur J Radiol 36(3):123-125

72. Tran A, Prentice D, Chan M (2011) Tophaceous gout of the odontoid process causing glossopharyngeal, vagus, and hypoglossal nerve palsies. Int J Rheum Dis 14(1):105-108
73. Konatalapalli RM, Demarco PJ, Jelinek JS et al (2009) Gout in the axial skeleton. J Rheumatol 36(3):609-613

74. Zheng ZF, Shi HL, Xing Y, Li D, Jia JY, Lin S (2015) Thoracic cord compression due to ligamentum flavum gouty tophus: a case report and literature review. Spinal Cord 53(12):881-886

75. Nicolaou S, Liang T, Murphy DT, Korzan JR, Ouellette H, Munk P (2012) Dualenergy CT: a promising new technique for assessment of the musculoskeletal system. AJR Am J Roentgenol 199(5 Suppl):S78-86

76. Parikh P, Butendieck R, Kransdorf M, Calamia K (2010) Detection of lumbar facet joint gouty arthritis using dual-energy computed tomography. J Rheumatol 37(10):2190-2191

77. Chan RLS, Chan CH, Chan HF, Pan NY (2019) The many facets of neuropathic arthropathy. BJR Open 1(1):20180039

78. Ledbetter LN, Salzman KL, Sanders RK, Shah LM (2016) Spinal neuroarthropathy: pathophysiology, clinical and imaging features, and differential diagnosis. Radiographics 36(3):783-799

79. Lee D, Dahdaleh NS (2018) Charcot spinal arthropathy. J Craniovertebr Junction Spine 9(1):9-19

80. Martín Noguerol T, Luna Alcalá A, Beltrán LS, Gómez Cabrera M, Broncano Cabrero J, Vilanova JC (2017) Advanced MR imaging techniques for differentiation of neuropathic arthropathy and osteomyelitis in the diabetic foot. Radiographics 37(4):1161-1180

81. Aebli N, Pötzel T, Krebs J (2014) Characteristics and surgical management of neuropathic (Charcot) spinal arthropathy after spinal cord injury. Spine J 14(6):884-891

82. Staloch MA, Hatem SF (2007) Charcot spine. Emerg Radiol 14(4):265-269

83. Jones EA, Manaster BJ, May DA, Disler DG (2000) Neuropathic osteoarthropathy: diagnostic dilemmas and differential diagnosis. Radiographics. 20 Spec No:S279-93

84. Jacobs WB, Bransford RJ, Carlo Bellabarba C, Chapman JR (2012) Surgical management of Charcot spinal arthropathy: a single-center retrospective series highlighting the evolution of management. J Neurosurg Spine 17(5):422-431

85. Wagner SC, Schweitzer ME, Morrison WB, Przybylski GJ, Parker L (2000) Can imaging findings help differentiate spinal neuropathic arthropathy from disk space infection? Initial experience. Radiology 214(3):693-699

86. Himuro H, Kurata S, Nagata S et al (2020) Imaging features in patients with SAPHO/CRMO: a pictorial review. Jpn J Radiol 38(7):622-629

87. Leone A, Cassar-Pullicino VN, Casale R, Magarelli N, Semprini A, Colosimo C (2015) The SAPHO syndrome revisited with an emphasis on spinal manifestations. Skeletal Radiol 44(1):9-24

88. Mc Gauvran AM, Kotsenas AL, Diehn FE, Wald JT, Carr CM, Morris JM (2016) SAPHO syndrome: imaging findings of vertebral involvement. AJNR Am J Neuroradiol 37(8):1567-1572

89. Nachtigal A, Cardinal E, Bureau NJ, Sainte-Marie LG, Milette F (1999) Vertebral involvement in SAPHO syndrome: MRI findings. Skeletal Radiol 28(3):163-168

90. Akisue T, Yamamoto T, Marui T et al (2002) Lumbar spondylodiscitis in SAPHO syndrome: multimodality imaging findings. J Rheumatol 29(5):1100-1101

91. Toussirot E, Dupond JL, Wendling D (1999) Ann spondylodiscitis in SAPHO syndrome. A series of eight cases. Rheum Dis 56(1):52-58

92. Taljanovic MS, Hunter TB, Wisneski RJ et al (2009) Imaging characteristics of diffuse idiopathic skeletal hyperostosis with an emphasis on acute spinal fractures: review. AJR Am J Roentgenol 193(3 Suppl):S10-S19

93. Kumaran SP, Thippeswamy PB, Reddy BN, Neelakantan S, Viswamitra S (2019) An institutional review of tuberculosis spine mimics on MR imaging: cases of mistaken identity. Neurol India 67(6):1408-1418

94. Dass B, Puet TA, Watanakunakorn C (2002) Tuberculosis of the spine (Pott's disease) presenting as 'compression fractures. Spinal Cord 40(11):604-608

95. Kumar Y, Gupta N, Chhabra A, Fukuda T, Soni N, Hayashi D (2017) Magnetic resonance imaging of bacterial and tuberculous spondylodiscitiswith associated complications and non-infectious spinal pathology mimicking infections: a pictorial review. BMC Musculoskelet Disord 18(1):244

\section{Publisher's Note}

Springer Nature remains neutral with regard to jurisdictional claims in published maps and institutional affiliations. 